\title{
Factors Influencing Publication Rates of Abstracts Presented at the ADEA Annual Session \& Exhibition
}

\author{
Maria T.S. Galang, D.M.D., M.S.; Judy Chia-Chun Yuan, D.D.S., M.S.; \\ Damian J. Lee, D.D.S.; Valentim A.R. Barao, D.D.S., M.Sc.; \\ Nodesh Shyamsunder, B.D.S.; Cortino Sukotjo, D.D.S., Ph.D., M.M.Sc.
}

Abstract: Factors related to the path of abstracts from presentation at a conference to publication as a full article have been analyzed in the medical field, but only a few studies have been performed in dentistry. This study investigated the rate of publication of articles based on abstracts presented at the American Dental Education Association (ADEA) Annual Session \& Exhibition in 2002 and 2003 and the time lag to publication. This study also aimed to characterize the abstracts and subsequent articles and determine if there were any significant factors related to expansion of an abstract into a full manuscript. A total of 370 abstracts met the inclusion criteria and were examined for this study. Subsequent published articles were located using a standard PubMed search. Descriptive statistics and bivariate analyses were used to analyze the data collected $(\alpha=0.05)$. Results suggest that there was a low (19 percent) publication rate for articles based on abstracts presented at the meetings studied. The median time between abstract presentation and article publication was ten months. Factors that showed significant correlation to likelihood of article publication were multiple affiliations, presence of analytical statistics, and, to a lesser extent, funding. We suggest that presenters at these meetings should expand their abstracts into full manuscripts and seek to publish them in peer-reviewed journals for the benefit of the profession.

Dr. Galang is Assistant Professor of Orthodontics, College of Dentistry, University of Illinois at Chicago; Dr. Yuan is Clinical Assistant Professor, Department of Restorative Dentistry, College of Dentistry, University of Illinois at Chicago; Dr. Lee is Clinical Assistant Professor, Department of Restorative Dentistry, College of Dentistry, University of Illinois at Chicago; Dr. Barao is a Ph.D. student, Department of Dental Materials and Prosthodontics, Aracatuba Dental School, Univ. Estadual Paulista; Dr. Shyamsunder is a Research Scholar, University of Illinois at Chicago; and Dr. Sukotjo is Assistant Professor, Department of Restorative Dentistry, University of Illinois at Chicago, College of Dentistry. Direct correspondence and requests for reprints to Dr. Cortino Sukotjo, Department of Restorative Dentistry, University of Illinois at Chicago, College of Dentistry (MC 555), 801 South Paulina Street, Room 365B, Chicago, IL 60612-7211; 312-355-0360 phone; 312-996-3535 fax; csukotjo@uic.edu.

Keywords: abstract, publication rates, publication lag time, likelihood to publication, dental education

Submitted for publication 8/2/10; accepted 10/26/10

$\mathrm{T}$ The main goal of presentations at a scientific meeting is to share the results of research with the author's colleagues in the profession. ${ }^{1}$ Ultimately, the goal is to publish the data in order to reach beyond the meeting to the reading public. Numerous studies have examined abstract publication rates and factors affecting publication in peer-reviewed journals in the medical field. ${ }^{1-10}$ Unfortunately, a limited number of studies have been performed in dentistry, but those studies have found rates of publishing abstracts presented at scientific meetings ranging from 24 to 46 percent and have proposed a number of possible reasons for these rather low rates. ${ }^{11-14}$ Educational research, the focus of our study, is different from clinical or basic science research. Publication rates and other findings may vary due to its distinct approach and research methodology. No study of publication rates has been performed previously on the abstracts presented in dental education meetings.
The American Dental Education Association (ADEA) is home to more than 16,000 dental, allied dental, and advanced dental educators, students, and staff, who share the goal of advancing dental education. ${ }^{15}$ ADEA publishes in the Journal of Dental Education the abstracts for poster presentations made at the ADEA Annual Session \& Exhibition. The rate of subsequent publication of articles based on these abstracts in peer-reviewed journals has not previously been investigated. Therefore, the purposes of this study were 1) to describe the characteristics of the abstracts presented at the ADEA Annual Session \& Exhibition in 2002 and 2003; 2) to determine the proportion of abstracts presented that were published as full articles in peer-reviewed journals and the time lag to publication; and 3) to analyze the abstract characteristics related to subsequent article publication in the scientific literature. 


\section{Materials and Methods}

We chose a maximum of five years as a reasonable length of time to publish a full manuscript after abstract presentation. ${ }^{4,8,11,16,17}$ Thus, all the abstracts in 2002 and $2003^{18,19}$ related to dental education were chosen for this study. The abstracts were divided evenly among six investigators and were analyzed based on previous studies. ${ }^{11,20}$ To ensure consistency among the six investigators, calibration meetings were held on a regular basis to assess if the analyses coincided. Whenever there was a conflict or uncertainty, final group decisions were made.

\section{Analysis of Abstracts}

All abstracts that were not related to dental education were excluded in this study. The variables collected and tallied were 1) number of authors, 2) affiliation (university or institution where the research was conducted), 3) country of origin, 4) study design (observational or experimental), 5) study outcome (positive, negative, or neutral), 6) statistics (descriptive or analytical), and 7) funding: government (e.g., National Institutes of Health), foundation (e.g., American Dental Association Foundation), university, or industry (e.g., dental product company).

The study outcomes were categorized according to Hasenboehler et al. ${ }^{21}$ Positive outcomes were defined as those that resulted in a significant difference between control and treatment groups as well as favorable effects and recommendations. Negative outcomes were those in which there were significant differences between the groups but with negative conclusions or undesirable outcomes. Neutral outcomes were those with no significant differences between groups and no obvious deduction. Source of funding support was defined based on Shah et al. ${ }^{22}$ Industry funding referred to a private manufacturer of a product or technology, as opposed to private foundation or federal funding. Multiple funding sources were categorized according to the first mentioned funding source in the study. For purposes of this study, multiple affiliations were synonymous with collaboration and were recorded as any abstract that originated from more than one institution.

\section{Analysis of Full Articles}

Next, a standard PubMed search ${ }^{11}$ was conducted using the authors' names to search for abstracts that were subsequently published as full articles in peer-reviewed journals. When more than one result was found, a follow-up search was initiated utilizing the Boolean operator (AND) to combine authors and keywords from the abstract. ${ }^{12}$ The definition of "subsequently published" was modified based on Toma et al., ${ }^{6}$ who defined the target as an article written by at least one of the senior authors (first and/or last), containing the same topic and/or intervention, and published in a peer-reviewed journal.

We calculated the time from publication of abstract to journal publication of the full article in months and recorded the journal of publication. Those articles published prior to the respective ADEA Annual Session \& Exhibition were classified as zero $(0)$ months to publication.

Data were collected and entered into a spreadsheet (Microsoft Excel 2007, Seattle, WA). Statistical software (Statistical Package for the Social Sciences, version 17.0; SPSS Inc., Chicago, IL) was used for descriptive and statistical analyses. For all included abstracts, mean, median, and range were calculated for number of authors. Frequency and percentages were calculated for geographic origin of the article, study design, statistics analysis, study outcomes, sources of funding, and affiliation. The mean and median time between abstract presentation and article publication was calculated. The duration of time to publication was divided into one-year increments up to five or more years from the time of abstract presentation, based on Dahloff et al. ${ }^{12}$ Numbers of abstract presentations and article publications were tabulated based on the country and affiliation of the authors. A logistic regression analysis was performed to evaluate the association of publication and the variables (study design, affiliation, funding, study outcome, statistics). Statistical significance was defined as $p<0.05$.

\section{Results}

A total of 371 abstracts were examined. Two hundred and thirteen posters were presented at the 2002 ADEA Annual Session \& Exhibition, and 158 posters were presented at the 2003 ADEA Annual Session \& Exhibition. One abstract was excluded because it was not related to dental education, leaving 370 abstracts that met the inclusion criteria. The abstract characteristics are shown in Table 1. The median number of authors per abstract was three (range of one to eight). The majority of the abstracts ( 95 percent) originated from the United States. Seventyseven percent of the abstracts were observational 
in nature. More than three-quarters of the abstracts specified statistical analysis as part of the methods. Of the abstracts that included statistics, descriptive statistics were utilized twice as much as analytical statistics. The majority of the studies reported positive outcomes, and 92 percent of the abstracts did not report any source of funding. Finally, only 8 percent reported multiple affiliation or collaboration.

Of the 370 abstracts, seventy-one (19 percent) were published as full articles in peer-reviewed publications. The average time to full article publication was sixteen months, with a median of ten months. More than 50 percent of the articles were published within the first year after the poster presentation (Figure 1). Of the published articles, the majority $(\mathrm{n}=51$, 72 percent) were published in the Journal of Dental Education (JDE), followed by the Journal of Dental Hygiene ( $\mathrm{n}=8,11$ percent) (Figure 2).

The proportion of published articles based on authors' country is shown in Table 2. The articles' authors were mostly from the United States. Tables 3 and 4 show the institutional affiliations of the authors with the top ten number of abstracts and the top ten number of published articles.

Bivariate analyses for predictors of publication showed significant positive associations with collaboration (multi-affiliation studies) (OR 2.9, $\mathrm{p}=0.01$ ) and use of analytic statistics (OR 2.9, p<0.0001) (Table 5). Although not significant, abstracts that were funded or used statistics were 1.6 and 1.6 times more likely to be published, respectively.

\section{Discussion}

\section{Abstract Characteristics}

Because members of ADEA are mostly U.S. academicians, ${ }^{15}$ it is not surprising that the majority of the abstracts and published articles were by authors in the United States. It is worth noting that, among the abstracts, almost 8 percent had multiple affiliations, which is higher than the 2 percent found in a previous study on the content of dental education journals. ${ }^{23}$

Most of the abstracts reported positive outcomes. However, in our study, no association between positive outcome and likelihood of publication was found. Previous studies have reported that positive outcome studies are more likely to be published, and it has been suggested that this phenomenon may create a problem for evidence-based research as an incomplete perspective is available for reference. ${ }^{1,7}$

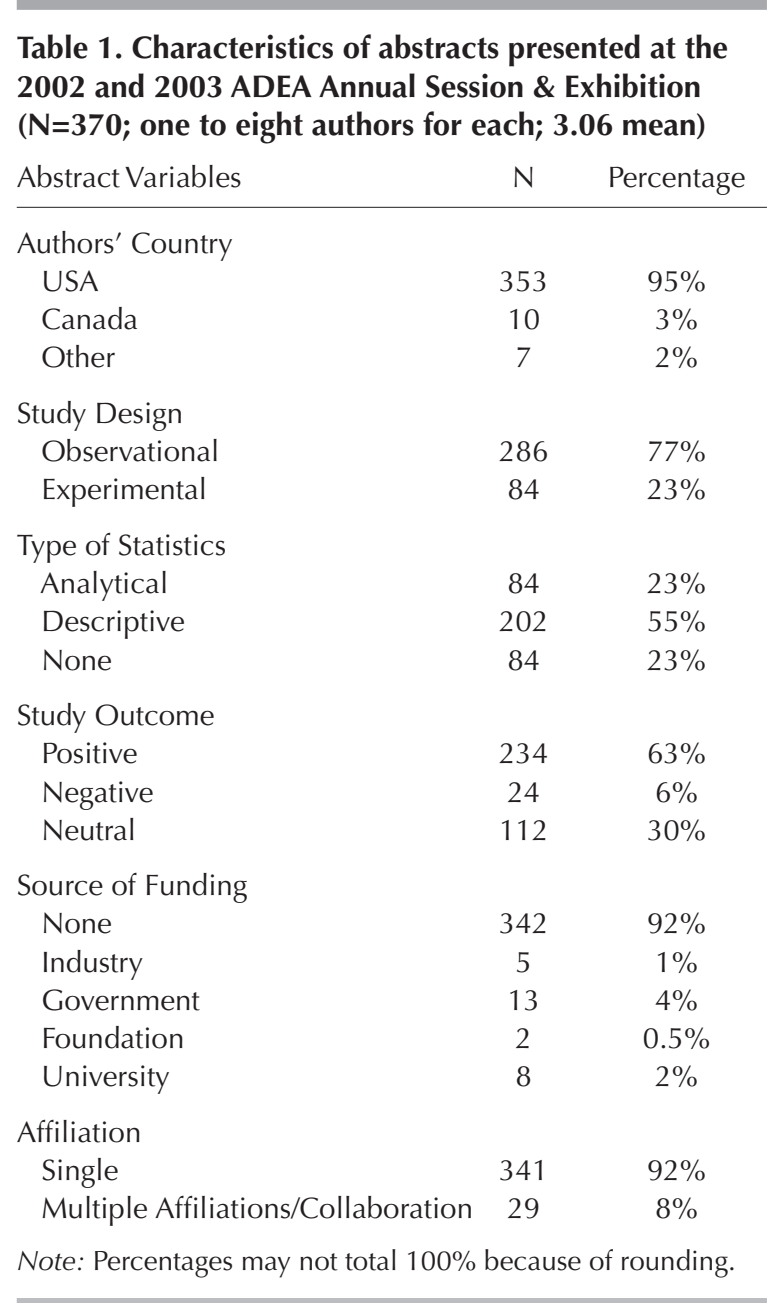

Crawford et al. recently described the increasing trend of certain tests to determine publication bias and the need for implementing such tests in reviewing articles for publication. ${ }^{24}$ This is important for protecting the reliability of scientific publications and subsequently protecting the public against unwarranted clinical decisions based on biased publications. The results of our study did not identify any bias toward positive outcomes in the dental education literature we examined.

Our study demonstrates that only three of the top ten abstract affiliations coincided with the top ten publication affiliations (Tables 3 and 4). Some institutions that present abstracts at a high rate appear to be more successful at publishing articles based on abstract presentations than others. This might reflect the differing research, education, and publication missions of academic institutions.

The number of abstracts that reported funding was low, which reflects the limited funding available 


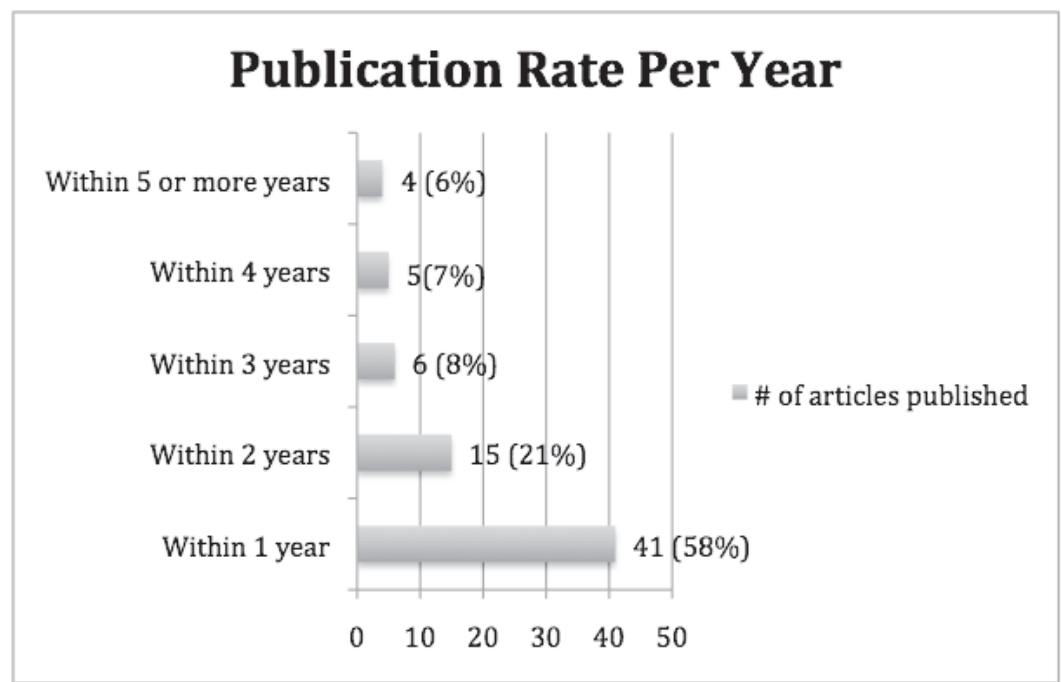

Figure 1. Publication rates by number of years from abstract presentation to full-length article publication, for abstracts presented at the 2002 and 2003 ADEA Annual Session \& Exhibition

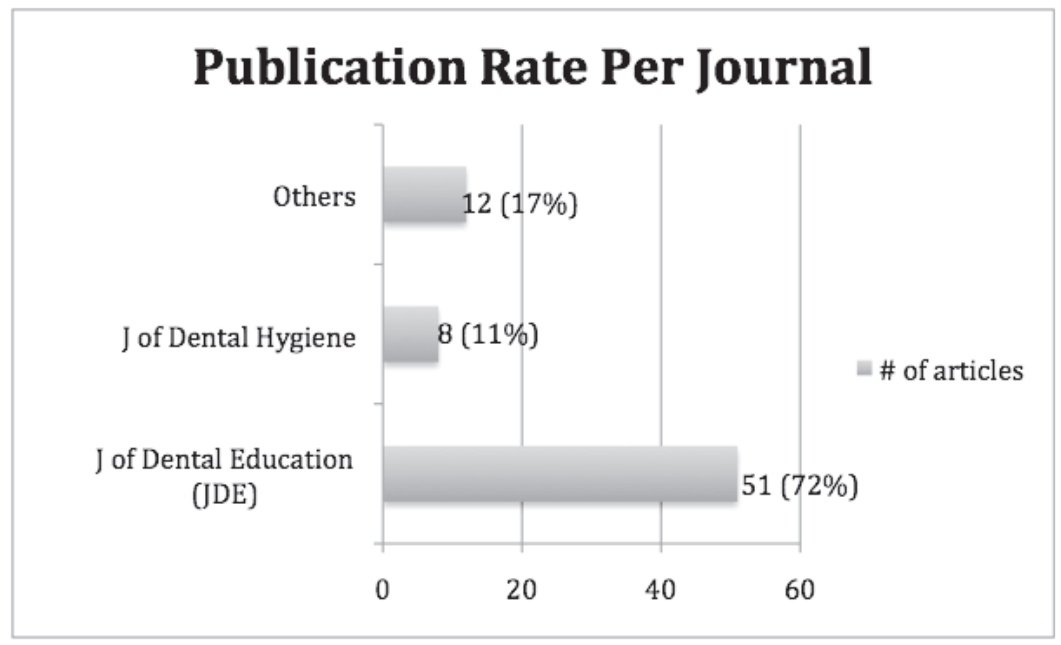

Figure 2. Publication rates of full-length articles based on abstracts presented at the 2002 and 2003 ADEA Annual Session \& Exhibition 
Table 2. Proportion of publication of abstracts and resulting articles by country

\begin{tabular}{lcccc} 
Country & $\begin{array}{c}\text { Number of } \\
\text { Abstracts }\end{array}$ & $\begin{array}{c}\text { Number of } \\
\text { Articles }\end{array}$ & $\begin{array}{c}\text { Percentage of Published } \\
\text { Articles from Number of Abstracts }\end{array}$ & $\begin{array}{c}\text { Percentage of Total } \\
\text { Articles }(\div 71)\end{array}$ \\
\hline USA & 356 & 68 & $19 \%$ & $96 \%$ \\
Canada & 10 & 3 & $30 \%$ & $4 \%$ \\
Others & 6 & 1 & $17 \%$ & $1 \%$
\end{tabular}

Note: Others include Australia, the UK, and Vietnam. Total is greater than 370 due to multiple countries of origin per study. Percentage of total articles does not total $100 \%$ because of rounding.

Table 3. Percentage of published articles by author's affiliation, based on institutions with top ten number of abstracts

\begin{tabular}{lcccc} 
& $\begin{array}{c}\text { Number of } \\
\text { Abstracts }\end{array}$ & $\begin{array}{c}\text { Number of } \\
\text { Articles }\end{array}$ & $\begin{array}{c}\text { Percentage of Published } \\
\text { Articles from Abstracts }\end{array}$ & $\begin{array}{c}\text { Percentage of Total } \\
\text { Articles (total=71) }\end{array}$ \\
\hline University of Kentucky & 21 & $3(2$ multi) & $14 \%$ & $4 \%$ \\
University of Michigan & 19 & $5(1$ multi) & $26 \%$ & $7 \%$ \\
University of the Pacific & 19 & 4 & $21 \%$ & $6 \%$ \\
University of Medicine and Dentistry of New Jersey & 16 & 2 & $12 \%$ & $3 \%$ \\
West Virginia University & 15 & 0 & $8 \%$ & 0 \\
New York University & 13 & 2 & $8 \%$ & $3 \%$ \\
Ohio State University & 13 & 2 & $8 \%$ & $3 \%$ \\
University of Missouri-Kansas City & 13 & 2 & $8 \%$ & $3 \%$ \\
University of Illinois at Chicago & 12 & 1 & $9 \%$ & $1 \%$ \\
Meharry Medical College & 11 & 1 & $1 \%$
\end{tabular}

Note: Articles with multiple affiliations are noted in parentheses.

Table 4. Percentage of published articles by author's affiliation, based on institutions with top ten number of articles

\begin{tabular}{lcccc} 
& $\begin{array}{c}\text { Number of } \\
\text { Abstracts }\end{array}$ & $\begin{array}{c}\text { Number of } \\
\text { Articles }\end{array}$ & $\begin{array}{c}\text { Percentage of Published } \\
\text { Articles from Abstracts }\end{array}$ & $\begin{array}{c}\text { Percentage of Total } \\
\text { Articles (total=71) }\end{array}$ \\
\hline University of California, Los Angeles & 10 & 5 & $50 \%$ & $7 \%$ \\
University of Pennsylvania & 9 & 5 & $56 \%$ & $7 \%$ \\
University of Michigan & 19 & $5(1$ multi) & $26 \%$ & $7 \%$ \\
University of the Pacific & 19 & 4 & $21 \%$ & $6 \%$ \\
University of Florida & 9 & 3 & $33 \%$ & $4 \%$ \\
University of lowa & 9 & $3(1$ multi) & $33 \%$ & $3 \%$ \\
Harvard School of Dental Medicine & 9 & 2 & $22 \%$ & $3 \%$ \\
New York University & 13 & 2 & $15 \%$ & $3 \%$ \\
Oregon Health \& Science University & 6 & 2 & $33 \%$ & $3 \%$ \\
Temple University & 10 & 2 & $20 \%$ & \\
Note: Articles with multiple affiliations are noted in parentheses. & & & \\
\hline
\end{tabular}

from governmental institutions and universities for dental education. Only 1 percent of the abstracts in our study were industry-funded, possibly due to the small number of industries involved in dental education research. In a recent content analysis of two dental education journals, a low (30 percent) rate of funding was also reported. ${ }^{23}$ The topic of dental education has a limited audience, so funding agencies may find these topics not critical for funding.

\section{Publication Rate and Time Lag to Article Publication}

The culmination of any research endeavor is the publication of results in a peer-reviewed journal in order to contribute to evidence-based decision making. ${ }^{11,25}$ The ADEA abstracts are peer-reviewed and published in the $J D E$; however, this brief, preliminary publication is not the same as the publica- 
Table 5. Analysis of factors related to abstracts leading to published articles

\begin{tabular}{lccccc} 
Factor & Level & Unpublished & Published & P-value & Odds Ratio (95\% Cl) \\
\hline Study Design & Observational & $234(82 \%)$ & $52(18 \%)$ & 0.365 & 1.00 \\
& Experimental & $65(77 \%)$ & $19(23 \%)$ & & $1.3(0.7,2.4)$ \\
Collaboration & Yes & $18(62 \%)$ & $11(38 \%)$ & 0.01 & $2.9(1.3,6.4)$ \\
(multi-affiliation) & No & $281(82 \%)$ & $60(18 \%)$ & & 1.00 \\
Funding & Yes & $20(71 \%)$ & $8(29 \%)$ & 0.195 & $1.8(0.7,4.2)$ \\
& No & $279(82 \%)$ & $63(18 \%)$ & & 1.00 \\
Study Outcome & Neutral & $87(78 \%)$ & $25(22 \%)$ & 0.245 & $1.4(0.8,2.4)$ \\
& Positive & $194(83 \%)$ & $40(17 \%)$ & 0.339 & $1.7(0.6,4.3)$ \\
\multirow{2}{*}{ Statistics-1 } & Negative & $18(75 \%)$ & $6(25 \%)$ & 0.057 & $2.1(1.0,4.1)$ \\
& Present & $225(79 \%)$ & $60(21 \%)$ & 0.00 & 1.00 \\
Statistics-2 & Absent & $74(87 \%)$ & $11(13 \%)$ & & 1.00
\end{tabular}

Note: Statistics-2 breaks down those abstracts with statistics present into Descriptive and Analytical; thus, total is 60 (not 71 ).

tion of research in a full-length article, which was the focus of this study. Of the abstracts presented at two consecutive ADEA meetings, we found that less than 20 percent were subsequently published as full-length articles. This result is much lower than the 40 to 70 percent publication rates reported in the medical literature. ${ }^{1,4,7,20}$ It is possible that this lower publication rate is related to the dental or educational content of the posters. Prior studies have attributed low publication rates to lack of time, low priority, lack of participation by coauthors, study still ongoing, and methodological limitations, with lack of time being the main reason cited. ${ }^{14}$ Since educational research is the foundation for progression in training health professionals, it is crucial to have dental education studies presented in peer-reviewed journals in order to disseminate effective educational methods. ${ }^{11,13}$ Educators and researchers should be encouraged and supported by their senior investigators or supervisors to prepare full manuscripts following their poster presentations. ${ }^{1}$

The mean number of months from abstract presentation to publication of a full-length article in a peer-reviewed journal was sixteen months, with a median of ten months. Compared to the mean of sixteen months reported by Sebe ${ }^{26}$ and the twentythree months reported by Bagheri et al., ${ }^{11}$ this shorter time period indicates that the ADEA abstracts are published as full articles fairly rapidly if they are published at all. A possible explanation for the varied lag times may be differences in the duration of journal review processes. ${ }^{27}$
Since the official journal of ADEA is the $J D E$, it is not surprising that most of the abstracts were published in that journal. In the United States, the $J D E$ is the only dental journal that targets mainly dental educators. This may have a negative effect on the rate of publication of articles based on abstracts due to limited avenues for submission. ${ }^{25}$ The addition of more journals for dental education research may increase acceptance of manuscripts and thus raise the publication rate on dental education topics, but considering the limited readership, adding new journals may be highly unlikely.

\section{Abstract Characteristics Related to Publication}

This study suggests that the more rigorous abstracts were more likely to be published as full articles since those abstracts with collaborations or multiple affiliations and display of statistical analyses were those more likely to result in article publication. Furthermore, abstracts with analytical statistics had a higher likelihood of publication as full articles than those that utilized descriptive statistics.

Past research has demonstrated that collaboration has a positive impact on the quality of research ${ }^{28,29}$ Figg et al. explained the positive impact of collaboration as decreasing research expenditures while maximizing productivity. ${ }^{28}$ The fact that collaboration has a positive effect on likelihood of publication may be due to multiple experts providing different valid insights, providing greater impact on 
refining the topics of study. In an interesting finding, Rosenzweig et al. identified international collaborations as a predictor for funding and publication. ${ }^{29}$ They found that authors who had collaborators outside the United States were 3.3 times more likely to get funded. In our study, possibly due to the meeting venue and membership, most of the collaborations were within the United States or with Canada. Only one study out of eleven with multiple affiliations was an international collaboration outside of North America (with one UK and two U.S. institutions). As the field of dental education becomes more globally oriented, more international collaboration may be explored in the future.

Presence of funding has also been associated with the likelihood of having articles published. ${ }^{4,30}$ Presumably, funding agencies have a requirement for reporting, whether presentation or publication, thus motivating funded investigators to publish their results. In our study, funding had no statistically significant association with publication as full articles, although it is worth mentioning that the odds ratio of getting published almost doubled with the presence of funding.

\section{Limitations of the Study}

This study did not record abstract topics, which may reveal certain associations with publication rate. ${ }^{1,23}$ Our study was based on abstracts chosen for presentation at the ADEA Annual Session \& Exhibition; since abstracts that were submitted but rejected were not considered in this study, the publication rate may be skewed. ${ }^{1,20}$

The search for published articles was limited to PubMed, and those journals not indexed in PubMed were not included for data analysis. This may underestimate the publication rates of articles based on the poster abstracts; however, it is not likely that articles regarding dental education will be missed in this kind of search. The methodology of the study was consistent with previous similar studies..$^{911-13,17,25,31}$

\section{Conclusion}

Our analysis of abstracts presented at the ADEA Annual Session \& Exhibition in 2002 and 2003 found that publication rates for subsequent dental education-related full-length articles were lower than those in medical fields. On a positive note, compared to the clinical medical literature, if a dental education article that grew out of an abstract gets published, it happens fairly soon after abstract presentation. Multiple affiliations and use of analytical statistics were associated with increased likelihood of article publication. This study suggests that dental education research has room for growth in terms of scientific publication.

\section{Acknowledgments}

The authors wish to thank Drs. Anne Koerber and John Crawford for their invaluable input in reviewing this manuscript.

\section{REFERENCES}

1. Sanossian N, Ohanian AG, Saver JL, Kim LI, Ovbiagele B. Frequency and determinants of nonpublication of research in the stroke literature. Stroke 2006;37(10):2588-92.

2. Hoag CC, Elterman DS, Macneily AE. Abstracts presented at the American Urological Association annual meeting: determinants of subsequent peer-reviewed publication. J Urol 2006;176(6 Pt 1):2624-9.

3. Lloyd EW, Geller JA, Iorio R, Yoon RS, Huo M, Macaulay W. Publication rates of scientific presentations at the American Association of Hip and Knee Surgeons annual meetings from 1996 to 2001. J Arthroplasty 2006;21(6 Suppl 2):2-5.

4. Peng PH, Wasserman JM, Rosenfeld RM. Factors influencing publication of abstracts presented at the AAOHNS annual meeting. Otolaryngol Head Neck Surg 2006;135(2): 197-203.

5. Smollin CG, Nelson LS. Publication of abstracts presented at 2001 NAACT. J Med Toxicol 2006;2(3):97-100.

6. Toma M, McAlister FA, Bialy L, Adams D, Vandermeer B, Armstrong PW. Transition from meeting abstract to full-length journal article for randomized controlled trials. JAMA 2006;295(11):1281-7.

7. Autorino R, Quarto G, Di Lorenzo G, De Sio M, Damiano R. Are abstracts presented at the EAU meeting followed by publication in peer-reviewed journals? A critical analysis. Eur Urol 2007;51(3):833-40.

8. Scherer RW, Langenberg P, von Elm E. Full publication of results initially presented in abstracts. Cochrane Database Syst Rev 2007(2):MR000005.

9. Kleweno CP, Bryant WK, Jacir AM, Levine WN, Ahmad CS. Discrepancies and rates of publication in orthopaedic sports medicine abstracts. Am J Sports Med 2008;36(10):1875-9.

10. Knobloch K. Discrepancies and rates of publication in orthopaedic sports medicine abstracts. Am J Sports Med 2009;37(3):e1-2; author reply e2.

11. Bagheri SC, Lenox N, Verschueren DS, Holmgren E, Kademani D, Bell RB, et al. Abstracts from the American Association of Oral and Maxillofacial Surgeons annual scientific meeting: proportion published and time to publication. J Oral Maxillofac Surg 2005;63(6):838-40. 
12. Dahlof G, Wondimu B, Maniere MC. Subsequent publication of abstracts presented at the International Association of Paediatric Dentistry meetings. Int J Paediatr Dent 2008;18(2):91-7.

13. Scholey JM, Harrison JE. Delay and failure to publish dental research. Evid Based Dent 2005;6(3):58-61.

14. Sprague S, Bhandari M, Devereaux PJ, Swiontkowski MF, Tornetta P 3rd, Cook DJ, et al. Barriers to full-text publication following presentation of abstracts at annual orthopaedic meetings. J Bone Joint Surg Am 2003;85A(1):158-63.

15. American Dental Education Association. About ADEA: who we are, 2010. At: www.adea.org/about_adea/who_ we_are/Pages/default.aspx. Accessed: August 2, 2010.

16. Hamlet WP, Fletcher A, Meals RA. Publication patterns of papers presented at the annual meeting of the American Academy of Orthopaedic Surgeons. J Bone Joint Surg Am 1997;79(8):1138-43.

17. Wang JC, Yoo S, Delamarter RB. The publication rates of presentations at major Spine Specialty Society meetings (NASS, SRS, ISSLS). Spine 1999;24(5):425-7.

18. American Dental Education Association 79th Annual Meeting, March 2-6, 2002, San Diego, California: abstracts. J Dent Educ 2002;66(2):247-345.

19. Abstracts of the American Dental Education Association Annual Session, March 8-12, 2003, San Antonio, Texas. J Dent Educ 2003;67(2):160-240.

20. Timmer A, Blum T, Lankisch PG. Publication rates following pancreas meetings. Pancreas 2001;23(2):212-5.

21. Hasenboehler EA, Choudhry IK, Newman JT, Smith WR, Ziran BH, Stahel PF. Bias towards publishing positive results in orthopedic and general surgery: a patient safety issue? Patient Saf Surg 2007;1(1):4.

22. Shah RV, Albert TJ, Bruegel-Sanchez V, Vaccaro AR, Hilibrand AS, Grauer JN. Industry support and correlation to study outcome for papers published in Spine. Spine 2005;30(9):1099-104.
23. Sukotjo C, Yuan JC, Bordage G. A content analysis of dental education research as reported in two journals. $\mathrm{J}$ Dent Educ 2010;74(10):1106-12.

24. Crawford JM, Briggs CL, Engeland CG. Publication bias and its implications for evidence-based clinical decision making. J Dent Educ 2010;74(6):593-600.

25. Donegan DJ, Kim TW, Lee GC. Publication rates of presentations at an annual meeting of the American Academy of Orthopaedic Surgeons. Clin Orthop Relat Res 2010;468(5):1428-35.

26. Sebel PSD. Abstracts from the IARS Clinical and Scientific Congress: proportion published and time to publication. Anesth Analg 2001;92(S110).

27. Greenberg D, Wacht O, Pliskin JS. Peer review in publication: factors associated with the full-length publication of studies presented in abstract form at the annual meeting of the Society for Medical Decision Making. Med Decis Making 2008;28(6):938-42.

28. Figg WD, Dunn L, Liewehr DJ, Steinberg SM, Thurman PW, Barrett JC, et al. Scientific collaboration results in higher citation rates of published articles. Pharmacotherapy 2006;26(6):759-67.

29. Rosenzweig JS, Van Deusen SK, Okpara O, Datillo PA, Briggs WM, Birkhahn RH. Authorship, collaboration, and predictors of extramural funding in the emergency medicine literature. Am J Emerg Med 2008;26(1):5-9.

30. Lynch JR, Cunningham MR, Warme WJ, Schaad DC, Wolf FM, Leopold SS. Commercially funded and United States-based research is more likely to be published; good-quality studies with negative outcomes are not. J Bone Joint Surg Am 2007;89(5):1010-8.

31. Bhandari M, Devereaux PJ, Guyatt GH, Cook DJ, Swiontkowski MF, Sprague S, et al. An observational study of orthopaedic abstracts and subsequent full-text publications. J Bone Joint Surg Am 2002;84A(4):615-21. 